Check for updates

Cite this: Chem. Sci., 2018, 9, 7096

๑ All publication charges for this article have been paid for by the Royal Society of Chemistry

\section{A synergistic LUMO lowering strategy using Lewis acid catalysis in water to enable photoredox catalytic, functionalizing $\mathrm{C}-\mathrm{C}$ cross-coupling of styrenes $\dagger$}

\author{
Elisabeth Speckmeier, Patrick J. W. Fuchs and Kirsten Zeitler (DD*
}

Easily available $\alpha$-carbonyl acetates serve as convenient alkyl radical source for an efficient, photocatalytic cross-coupling with a great variety of styrenes. Activation of electronically different $\alpha$-acetylated acetophenone derivatives could be effected via LUMO lowering catalysis using a superior, synergistic combination of water and (water-compatible) Lewis acids. Deliberate application of $f a c-\operatorname{Ir}(\mathrm{ppy})_{3}$ as photocatalyst to enforce an oxidative quenching cycle is crucial to the success of this (umpolung type) transformation. Mechanistic particulars of this dual catalytic coupling reaction have been studied in detail using both Stern-Volmer and cyclic voltammetry experiments. As demonstrated in more than 30 examples, our water-assisted LA/photoredox catalytic activation strategy allows for excess-free, equimolar radical cross-coupling and subsequent formal Markovnikov hydroxylation to versatile 1,4-difunctionalized products in good to excellent yields.

Received 12th May 2018

Accepted 17th July 2018

DOI: $10.1039 / \mathrm{c} 8 \mathrm{sc} 02106 \mathrm{f}$

rsc.li/chemical-science

\section{Introduction}

Visible light photocatalysis as a powerful tool for the selective generation of radicals has given rise to numerous unprecedented C-C-coupling reactions in recent years. ${ }^{1}$ Especially alkyl radicals ${ }^{2}$ have attracted great interest for the formation of highly functionalized natural products and pharmaceuticals. ${ }^{3}$ Back in 1985, Kellogg, one of the early pioneers of visible light photocatalysis, explored the reactivity of the electron deficient phenacyl radical generated by the photocatalytic single electron reduction of the corresponding phenacyl bromide. ${ }^{4}$ Since then, this electrophilic radical species has enabled the access to a variety of interesting radical trapping reactions for the implementation of new C-C-coupling transformations. ${ }^{5}$ However, phenacyl bromide is well known to promote radical polymerizations and also to be susceptible to nucleophilic substitutions (and hence enabling undesired polar reaction pathways) as for example, demonstrated for pyridines ${ }^{6}$ or under basic conditions. ${ }^{7}$ We hence assumed, that less activated $\alpha$-acetoxy acetophenone could be a promising alternative for radical C-C coupling reactions avoiding undesired pathways.

Especially, in addition, bromide itself cannot be considered as a photochemically innocent leaving group based on its

Institut für Organische Chemie, Universität Leipzig, Johannisallee 29, D-04103 Leipzig, Germany.E-mail: kzeitler@uni-leipzig.de

$\dagger$ Electronic supplementary information (ESI) available. See DOI: $10.1039 / \mathrm{c} 8 \mathrm{sc} 02106 \mathrm{f}$ redox properties: with an oxidation potential of only $0.66 \mathrm{~V} v s$. $\operatorname{SCE}\left(E_{\mathrm{ox}}\left(\mathrm{Br}^{*} / \mathrm{Br}^{-}\right)=0.66 \mathrm{~V}\right)$ mesolytically cleaved bromide anions can easily get oxidized to the corresponding bromine radicals and hence potentially may also form elemental $\mathrm{Br}_{2}$ by most common photocatalysts. ${ }^{8-10}$ Although, as the reduction potential of the corresponding $\alpha$-acetoxy acetophenone $\left(E_{\text {red }}=\right.$ $-1.72 \mathrm{~V} v s$. SCE) is more negative than the reduction potential of bromo acetophenone $\left(E_{\text {red }}=-1.45 \mathrm{~V} v s\right.$. SCE), we considered based on our recent C-O-bond cleaving studies, ${ }^{11}$ that this reduced affinity to accept electrons could, in addition, be beneficially utilized as a promising, assistant tool to enhance reaction control and selectivity by deliberate lowering of the carbonyl LUMO.

Using synergistic photoredox catalysis with amino organocatalysis MacMillan and co-workers could already demonstrate that $\alpha$-alkylation of aldehydes can be achieved with common $\alpha$-bromo acetophenone ${ }^{12}$ and, very recently, as well as with significantly less reactive $\alpha$-acetoxy derivatives as nontraditional radical precursors. ${ }^{13,14}$ We hence questioned, if such $\alpha$-acetoxy derived radicals as "alkylation reagent" could provide the required selectivity for a photocatalytic $\mathrm{sp}^{3}-\mathrm{sp}^{2}$ $\mathrm{C}-\mathrm{C}$ cross-coupling with styrenes followed by an oxidation to give the respective Markovnikov-type functionalized products (Scheme 1). This challenging photocatalytic/radical polar crossover reaction would offer unprecedented access to 1,4-functionalized synthons, such as $\gamma$-hydroxyketones, being versatile building blocks for the synthesis of a variety of bioactive compounds. ${ }^{16}$ 


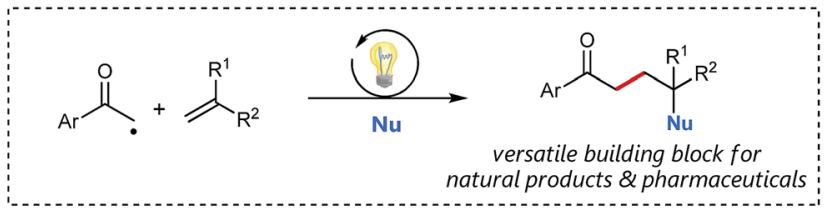

reductive radical generation

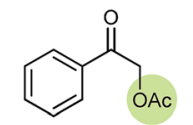

$\mathrm{E}_{\text {red }}=-1.72 \mathrm{~V}$

LUMO lowering necessary

easily accessible
stable under nucleophilic and basic conditions
photochemically innocent leaving group

Scheme 1 Design plan for a functionalizing $\mathrm{sp}^{3}-\mathrm{sp}^{2}$-photocatalytic cross-coupling reaction.

\section{Results and discussion}

Based on our previous experience in $\mathrm{C}-\mathrm{O}$-bond activation, ${ }^{\mathbf{1 1}}$ we approached our cross-coupling investigations right from the beginning with a focus on mechanism, especially considering

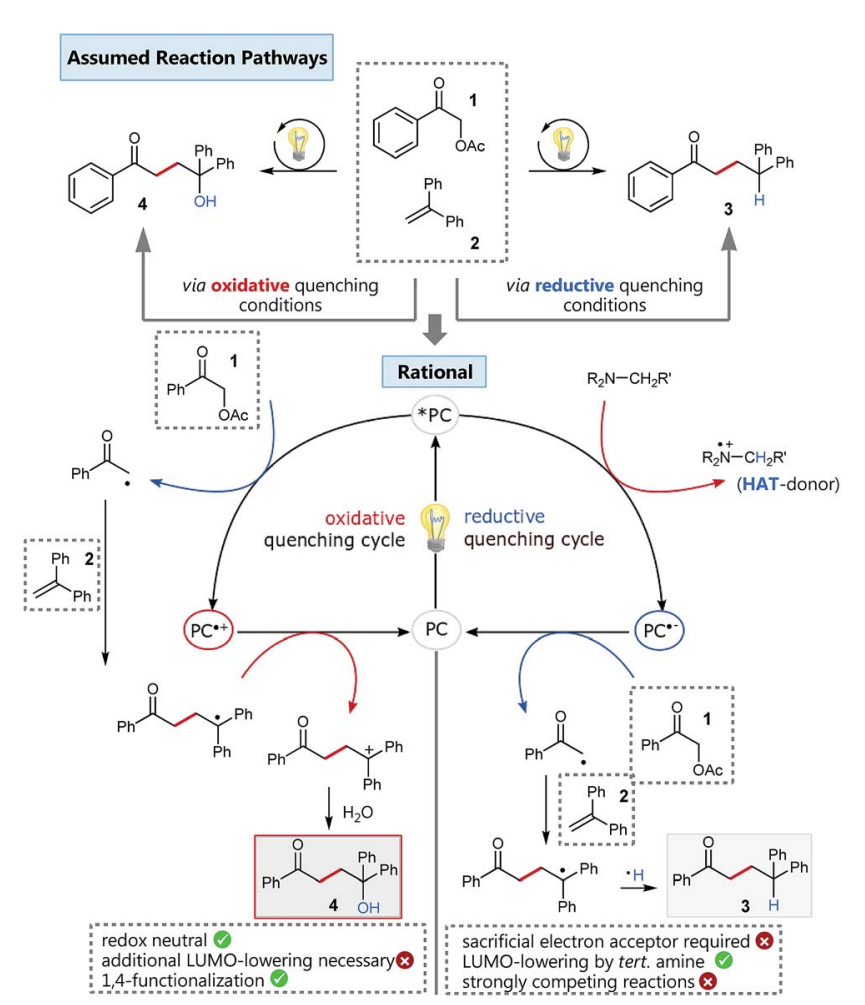

Scheme 2 Oxidative vs. reductive quenching conditions for the $\mathrm{C}-\mathrm{C}$ coupling of $\alpha$-acetoxy acetophenone and 1,1-diphenylethylene and simplified comparison of the corresponding different reaction pathways. Oxidative quenching conditions: $\mathrm{fac}-\operatorname{Ir}(\mathrm{ppy})_{3}, 0.5 \mathrm{mmol} 1,1.0 \mathrm{mmol} 2$ in $\mathrm{MeCN} / \mathrm{H}_{2} \mathrm{O} 4: 1$, irradiation with blue LEDs; yield of isolated product 4: $33 \%$. Reductive quenching conditions: $4 \mathrm{CzIPN}^{15} 1.5$ equiv. $\mathrm{NBu}_{3}$, $0.5 \mathrm{mmol} 1,1.0 \mathrm{mmol} 2 \mathrm{in} \mathrm{MeCN} / \mathrm{H}_{2} \mathrm{O} 4: 1$, irradiation with blue LEDs; yield of isolated product 3: $83 \%$. the crucial role of the quenching cycles of the photocatalyst (Scheme 2). ${ }^{17}$ Initial test reactions employing simple oxidative (Scheme 2/left) and reductive quenching conditions (Scheme 2/ right) for the coupling of $\alpha$-acetoxy acetophenone (1) as radical precursor and 1,1-diphenylethylene (2) as well-established activated coupling partner, ${ }^{18}$ confirmed our hypothesis, that a reductive quenching cycle would be inappropriate for this intended reaction.

Using tertiary amines as reductive quenchers typically offers the great advantage of an extensive LUMO-lowering of the carbonyl group via hydrogen bond/PCET ${ }^{19}$ activation or 2-center/3-electron interaction, ${ }^{20}$ respectively, effected by the tertiary amine's radical cation. However, we expected that such a reductive quenching cycle would impede the necessary oxidation of the benzylic radical to the corresponding benzylic cation being crucial for achieving the targeted, additional Markovnikov functionalization. Two possible pathways for this supposed limitation could be considered to be operating: apart from a competitive oxidation of the reductive quencher (e.g. $\mathrm{R}_{3} \mathrm{~N}$ ), well-established HAT (hydrogen atom transfer) from the tertiary amine's radical cation, being present in increasing concentrations during the progress of the reaction, could operate as an additional detrimental pathway. As anticipated, no Markovnikov product was obtained while conducting the reaction with tributylamine as electron donor, following a reductive quenching cycle (Scheme 2/right). Instead, hydrogen atom abstraction took place as subsequent reaction step after the catalytic cycle to provide the coupling product 3 in an isolated yield of $83 \%$. However, our attempts to transfer these promising, "reductive quenching coupling conditions", which albeit miss the targeted additional functionalization, to less reactive styrenes (instead of our initial test substrate 1,1-diphenylethylene 2) were not met with success. Further competitive reaction pathways (Scheme 3) impede the coupling with styrene, such as the direct abstraction of a hydrogen atom from the reductive quencher by the phenacyl radical (product 5) (HAT), as well as the radical addition onto an enamine species derived from the degradation of the amine quencher providing the alternative aldehyde coupling product 6 via aminocatalysis (Scheme 3).

Fortunately, employing $f a c$-Ir(ppy) $)_{3}$ as photocatalyst in a redox neutral oxidative quenching cycle mediates the targeted functionalizing $\mathrm{C}-\mathrm{C}$ coupling reaction to yield the desired 1,4 -functionalized product 4 . Remarkably, the $\alpha$-acetoxy acetophenone (1) was reduced by $f a c-\operatorname{Ir}(\text { ppy })_{3}\left(E_{1 / 2}(\operatorname{Ir}(\mathrm{III}) * / \operatorname{Ir}(\mathrm{Iv}))=\right.$ $-1.73 \mathrm{~V}$ vs. SCE $)^{17 b}$ without further attempts to lower the

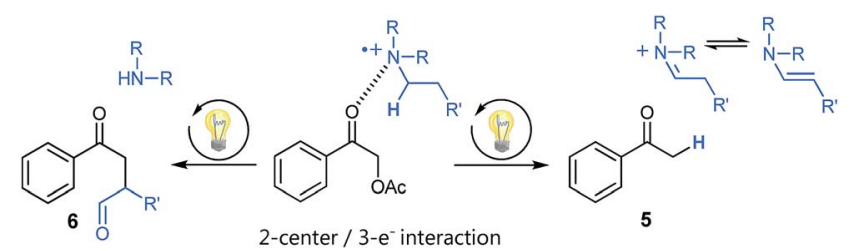

Scheme 3 Undesired side products present in cross-coupling reactions following a reductive quenching cycle. 
carbonyl LUMO. Although the reduction potential of 1 seems to be too negative for a direct reduction $\left(E_{\text {red }}=-1.72 \mathrm{~V} v s\right.$. SCE), we could already obtain $33 \%$ of the desired functionalized coupling product 4 . Notably, this preliminary finding indicated, that the carbonyl group may here even be significantly activated for reduction, respectively for a PCET-type reduction with water as omnipresent hydrogen bond donor under our aqueous conditions. ${ }^{21}$

Having this in mind, we initiated a detailed screening, again using styrene (7) as a more challenging, less activated coupling partner (Table 1). Additional to water as $\mathrm{H}$-bond donor present in our solvent mixture, we evaluated different activation modes for the LUMO lowering of carbonyl group, ${ }^{22}$ including Schreiner's thiourea, ${ }^{23}$ as well as different lanthanide-based, watercompatible Lewis acids. ${ }^{\mathbf{2 4 , 2 5}}$ Interestingly, the choice of the activation mode (entries 2 and 3), as well as the choice of the lanthanide Lewis acid (entries 5-9) seems to be insignificant for the coupling product's yield.

However, Schreiner's thiourea catalyst proved to be rather unstable under these photocatalytic conditions. To avoid large catalyst loadings and additional side products formed via the degradation of the thiourea catalyst, we decided to continue our investigations with neodymium triflate as Lewis acid in a dual activation, synergistic catalysis. ${ }^{26}$ Furthermore, the yield of coupling product could be dramatically increased by degassing the reaction mixture (entries 4 and 5), to 91\% (entry 9). Additionally, decreasing the styrene equivalents to an equimolar amount, as well as lowering the catalyst loading to $0.5 \mathrm{~mol} \%$ had no negative influence nor on the yield neither on the reaction time $(2 \mathrm{~h})$ (entry $10(92 \%))$. Notably, these optimized reaction conditions allow for equimolar cross-coupling of radical precursor 1 and styrene 7 to the 1,4-functionalized

Table 1 Optimization of oxidative quenching conditions for styrene cross-coupling

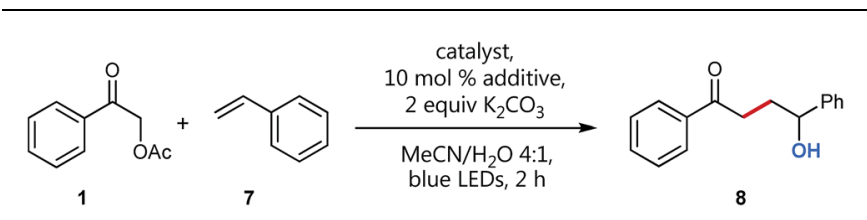

\begin{tabular}{|c|c|c|c|c|}
\hline Entry & Catalyst & Additive & $1: 7$ & Yield $^{a}$ \\
\hline $1^{b, c, d}$ & $1 \mathrm{~mol} \%$ fac- $\operatorname{Ir}(\mathrm{ppy})_{3}$ & Thiourea $^{e}$ & $1: 4$ & $19 \%$ \\
\hline $2^{b, c}$ & $1 \mathrm{~mol} \% f a c-\operatorname{Ir}(\mathrm{ppy})_{3}$ & Thiourea $^{e}$ & $1: 4$ & $45 \%$ \\
\hline $3^{b, c}$ & $1 \mathrm{~mol} \% f a c-\operatorname{Ir}(\mathrm{ppy})_{3}$ & $\mathrm{Yb}(\mathrm{OTf})_{3}$ & $1: 4$ & $46 \%$ \\
\hline $4^{c}$ & $1 \mathrm{~mol} \% f a c-\operatorname{Ir}(\mathrm{ppy})_{3}$ & $\mathrm{Yb}(\mathrm{OTf})_{3}$ & $1: 2$ & $58 \%$ \\
\hline 5 & $1 \mathrm{~mol} \% f a c-\operatorname{Ir}(\mathrm{ppy})_{3}$ & $\mathrm{Yb}(\mathrm{OTf})_{3}$ & $1: 2$ & $82 \%$ \\
\hline 6 & $1 \mathrm{~mol} \% f a c-\operatorname{Ir}(\mathrm{ppy})_{3}$ & $\operatorname{Er}(\mathrm{OTf})_{3}$ & $1: 2$ & $85 \%$ \\
\hline 7 & $1 \mathrm{~mol} \%$ fac- $\operatorname{Ir}(\mathrm{ppy})_{3}$ & $\mathrm{Gd}(\mathrm{OTf})_{3}$ & $1: 2$ & $88 \%$ \\
\hline 8 & $1 \mathrm{~mol} \%$ fac- $\operatorname{Ir}(\mathrm{ppy})_{3}$ & $\operatorname{Dy}(\mathrm{OTf})_{3}$ & $1: 2$ & $90 \%$ \\
\hline 9 & $1 \mathrm{~mol} \%$ fac- $\operatorname{Ir}(\mathrm{ppy})_{3}$ & $\mathrm{Nd}(\mathrm{OTf})_{3}$ & $1: 2$ & $91 \%$ \\
\hline 10 & $0.5 \mathrm{~mol} \%$ fac-Ir(ppy $)_{3}$ & $\mathrm{Nd}(\mathrm{OTf})_{3}$ & $1: 1$ & $92 \%$ \\
\hline
\end{tabular}

${ }^{a}$ Conditions: catalyst, $10 \mathrm{~mol} \%$ additive, 2 equiv. $\mathrm{K}_{2} \mathrm{CO}_{3}, 0.25 \mathrm{mmol} 1$, $0.25 \mathrm{mmol} 7$ in $1 \mathrm{~mL} \mathrm{MeCN} / \mathrm{H}_{2} \mathrm{O} 4: 1$, degassed, irradiation with blue LEDs, $2 \mathrm{~h}$, yield determined by GC-FID using mesitylene as internal standard. ${ }^{b} 20 \mathrm{~mol} \%$ additive. ${ }^{c}$ Without degassing. ${ }^{d} \mathrm{MeCN}$ as solvent. ${ }^{e}$ Schreiner's thiourea catalyst. product in excellent yield, avoiding typical side reactions, such as styrene polymerization or hydrogen abstraction of the $\alpha$ acetylated acetophenone.

The control reactions (Table 2) confirmed the decisive role of both catalyst and visible light, as without each no reaction occurred during $48 \mathrm{~h}$ of elongated reaction time (entries 1 and 2 ). The omission of Lewis acid (entry 3 ) decreases the yield to only $64 \%$. An experiment performed in acetonitrile without water, but offering $\mathrm{MeOH}$ as alternative nucleophile (entry 4), did not provide any of the corresponding methoxy adduct. In combination with entry 3 this clearly shows the synergistic interaction of both activation modes..$^{21,26}$ Water can lower the carbonyl LUMO only by weak hydrogen bonds, however greatly contributes to the success of the reaction by creating a twophase system, which additionally shifts the equilibrium to the cross-coupling process.

The catalytic amount of Lewis acid strongly enhances the effect on lowering the carbonyl's LUMO; this may also be in the context of the formation of Lewis acid water complexes to promote PCETs as well-known for $\mathrm{SmI}_{2}$-water systems. ${ }^{27,28}$ However, without the addition of water $\mathrm{Nd}(\mathrm{OTf})_{3}$ is almost insoluble in acetonitrile and therefore cannot effectively contribute to the carbonyl activation (entry 4). The exchange of the acetate leaving group with bromide (entry 6) significantly decreased the yield of the desired coupling product 8 to $38 \%$. While full conversion of the bromo acetophenone was still reached after $2 \mathrm{~h}$ of irradiation, numerous, not further determined side products were formed, clearly proving the crucial role of the radical source for this cross-coupling/ functionalization protocol. An additional test reaction using $\operatorname{Ir}(\mathrm{dtbbpy})(\mathrm{ppy})_{2}\left(\mathrm{PF}_{6}\right)$ as strongly reductive catalyst for reductive quenching cycles, but weaker reductive power of its excited state $(E(\operatorname{Ir}(\mathrm{III}) / \operatorname{Ir}(\mathrm{II}))=-1.51 \mathrm{~V}$ vs. $\mathrm{SCE} ; E(\operatorname{Ir}(\mathrm{III}) * / \operatorname{Ir}(\mathrm{IV}))=-0.96 \mathrm{~V} v s$.

\section{Table 2 Control experiments}

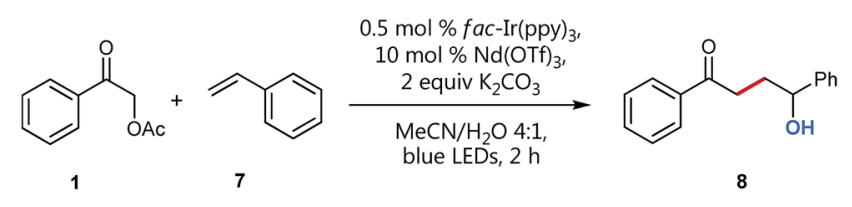

\begin{tabular}{lll}
\hline Entry & Deviation from the standard conditions & Yield $^{a}$ \\
\hline $1^{b}$ & No catalyst & $0 \%$ \\
$2^{b}$ & No light & $0 \%$ \\
3 & No Lewis acid & $64 \%$ \\
4 & No water, but MeOH & $0 \%{ }^{c}$ \\
5 & No base & $61 \%$ \\
6 & Bromoacetophenone as radical source & $38 \%$ \\
7 & Ir(dtbby)(ppy) ${ }_{2}\left(\mathrm{PF}_{6}\right)$ as catalyst & $0 \%$
\end{tabular}

${ }^{a}$ Conditions: $0.5 \mathrm{~mol} \%$ fac- $\operatorname{Ir}(\mathrm{ppy})_{3}, 10 \mathrm{~mol} \% \mathrm{Nd}(\mathrm{OTf})_{3}, 2$ equiv. $\mathrm{K}_{2} \mathrm{CO}_{3}$, $0.25 \mathrm{mmol} 1,0.25 \mathrm{mmol} 7$ in $1 \mathrm{~mL} \mathrm{MeCN} / \mathrm{H}_{2} \mathrm{O} 4: 1$, degassed, irradiation with blue LEDs, $2 \mathrm{~h}$, yield determined by GC-FID using mesitylene as internal standard. ${ }^{b} 48 \mathrm{~h}$ reaction time. ${ }^{c}$ Only minor conversion of $\mathbf{1}$; traces of 1,4-diphenylbut-3-en-1-one (corresp. alkene to 8) and dimerization product 1,4-diphenylbutane-1,4-dione were detected by GC/MS. 
SCE $)^{17 b}$ failed to provide any product and further confirms the oxidative quenching cycle of this cross-coupling.

We then set out to prove the synergistic combination of water and Lewis acid in a series of mechanistic studies. Initially, we wanted to "visualize" and somewhat quantify the LUMO lowering effect by cyclic voltammetry measurements ${ }^{29}$ to monitor the influence of different additives on the reduction potential (Fig. 1) and hence to gain a more detailed mechanistic understanding.

Insightfully, both the addition of water as well as of neodymium triflate results in a significant decrease of the measured reduction potential of $\alpha$-acetoxy acetophenone 1 . While without any additive the potential of 1 is slightly too high for a thermodynamically favorable reduction with $f a c$ - $\operatorname{Ir}(\mathrm{ppy})_{3}$, the solvent mixture (MeCN/water $4: 1(\mathrm{v} / \mathrm{v}))$ already lowers the reduction potential sufficiently to enable the reduction of 1 and hence points to the often neglected, however crucial role of solvents, especially water, for (photo)redox processes. ${ }^{30}$

Notably, the combination of both activation modes, the aqueous solvent system plus a water-compatible Lewis acid, ${ }^{27}$ significantly lowers the potential by $0.5 \mathrm{~V}$ and hence contributes to an even more exergonic electron transfer process.

Furthermore, we could confirm these observations by SternVolmer experiments (Fig. 2), also corroborating our initial studies with diphenylethylene (see also Scheme 2).

While quenching study A shows no relevant decrease in the photocatalyst's fluorescence with increasing concentrations of 1 in pure (dry) acetonitrile, only in quenching study B, performed in an acetonitrile/water mixture $(4: 1(\mathrm{v} / \mathrm{v}))$, the emission of fac-Ir(ppy $)_{3}$ is clearly quenched by $\alpha$-acetoxy acetophenone 1 . We further proved the importance of the exclusion of oxygen (Table 1, entries 4 and 5) in this reaction: quenching study $\mathrm{C}$ shows energy transfer to $\mathrm{O}_{2}$ for the singlet oxygen production ${ }^{31}$ to be a strongly preferred quenching pathway of $f a c-\operatorname{Ir}(\mathrm{ppy})_{3}$ in these solvent conditions.

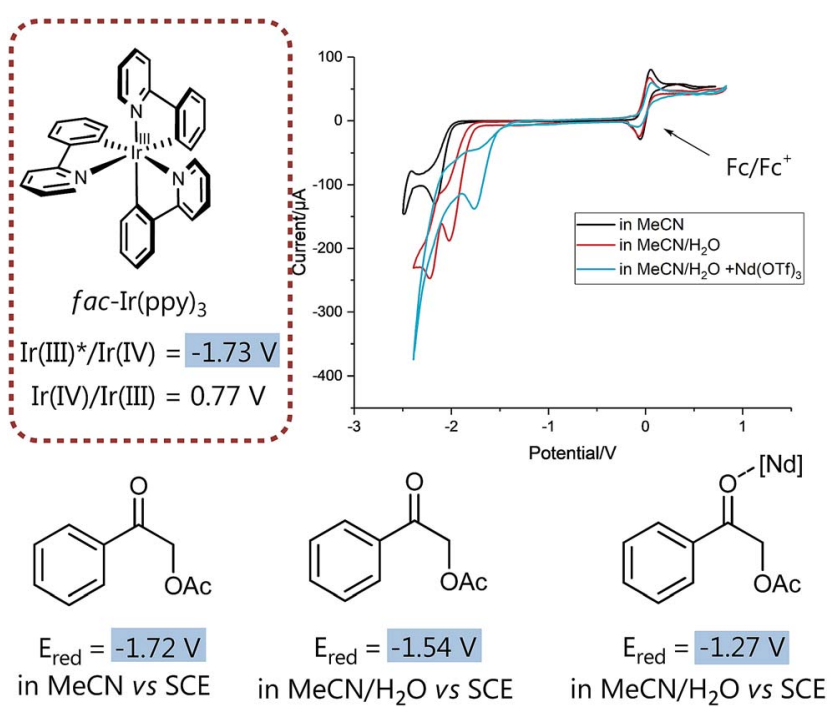

Fig. 1 LUMO-lowering effects on reduction potential of 1 subject to different conditions. For details on electrodes, concentration and measurement conditions see ESI.†

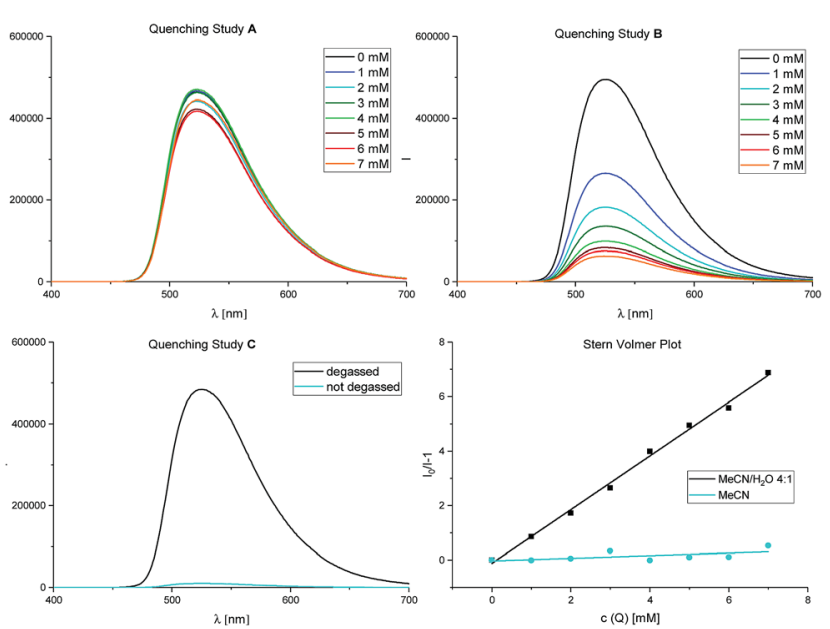

Fig. 2 Stern-Volmer quenching studies. Fluorescence spectra for fac-Ir(ppy $)_{3}(50 \mu \mathrm{M})$ with increasing amounts of $\alpha$-acetoxy acetophenone 1 (0-7 $\mathrm{mM})$ as quencher. Quenching study A: in $\mathrm{MeCN}$; quenching study $\mathrm{B}$ : in $\mathrm{MeCN} / \mathrm{H}_{2} \mathrm{O} 4$ : 1; quenching study $\mathrm{C}$ : presence of oxygen. For further details, see ESI. $\dagger$

Based on these studies and our experimental results, we propose the following mechanism for this functionalizing, radical $\mathrm{C}-\mathrm{C}$-coupling reaction (Scheme 4) starting with the excitation of the Ir catalyst followed by an oxidative quenching via single electron transfer to the activated carbonyl group of $\mathbf{1}$. The mesolytic cleavage of the $\mathrm{C}-\mathrm{O}$-bond leads to electron deficient radical 9, which can now attack the styrene. Subsequently, the newly created benzylic radical 10, which may be stabilized by intramolecular cyclization ${ }^{5 g}$ to radical $\mathbf{1 0}_{\text {cycl }}$ and hence suppress possible, undesired side reactions (polymerization etc.), can be oxidized by the $\operatorname{Ir}(\mathrm{Iv})$ species. Upon regeneration of the photocatalyst this results in a radical polar crossover to benzylic cation 11, respectively its cyclized variant $\mathbf{1 1}_{\text {cycl }}$. Final attack of water can then lead to the formation of the 1,4-ketohydroxy product.

Having optimized conditions and a mechanistic understanding at hand, we set out to examine the scope of the reaction starting with different styrenes (Scheme 5). Notably, all tested vinyl benzenes could successfully be coupled with the

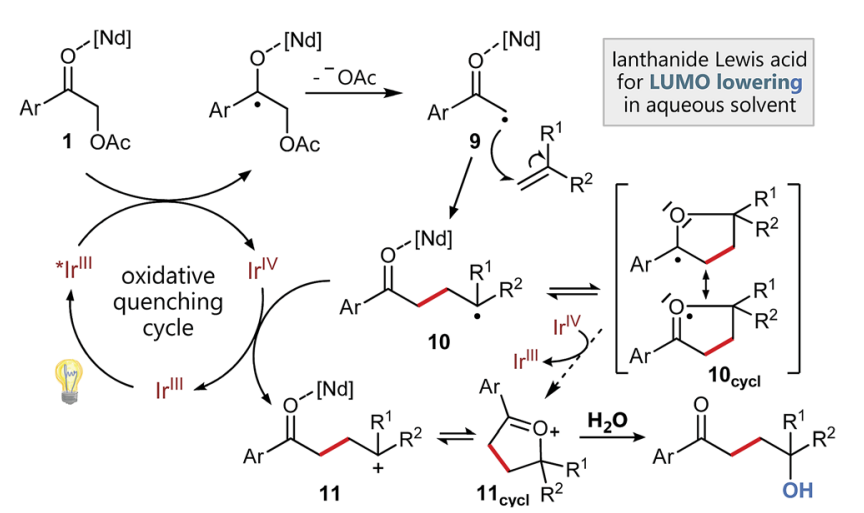

Scheme 4 Proposed mechanism. 


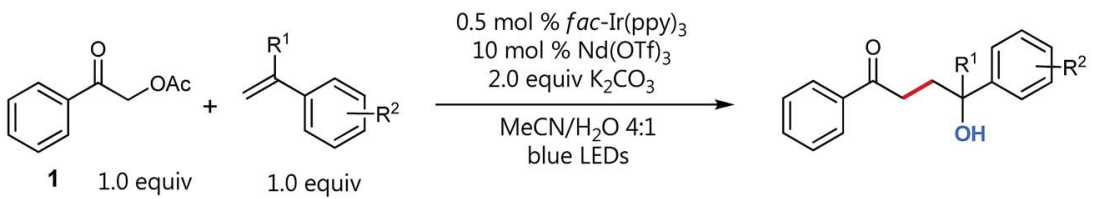<smiles>O=C(CCC(O)c1ccccc1)c1ccccc1</smiles>

8. $87 \%$<smiles>O=C(CCC(O)c1ccc(Br)cc1)c1ccccc1</smiles>

$12,80 \%$<smiles>O=C(CCC(O)c1cccc(Br)c1)c1ccccc1</smiles>

$13,70 \%$<smiles>O=C(CCC(O)c1ccccc1Br)c1ccccc1</smiles>

14, $72 \%$<smiles>O=C(CCC(O)c1ccc(F)cc1)c1ccccc1</smiles>

15, $96 \%$<smiles>COc1ccc(C(O)CCC(=O)c2ccccc2)cc1</smiles>

$16,86 \%$<smiles>CCc1ccc(C(O)CCC(=O)c2ccccc2)cc1</smiles>

$17,52 \%$<smiles>CC(=O)Oc1ccc(C(O)CCC(=O)c2ccccc2)cc1</smiles>

$18,82 \%$<smiles>CC(C)(C)c1ccc(C(O)CCC(=O)c2ccccc2)cc1</smiles>

$19,82 \%$<smiles>CC(O)(CCC(=O)c1ccccc1)c1ccccc1</smiles>

20, $86 \%$<smiles>O=C(CCC(O)(c1ccccc1)c1ccccc1)c1ccccc1</smiles>

4. $90 \%$

Scheme 5 Substrate scope for $\mathrm{C}-\mathrm{C}$-coupling with styrene derivatives. Conditions: 0.5 mol\% fac- $\operatorname{lr}(\mathrm{ppy})_{3}, 10 \mathrm{~mol} \% \mathrm{Nd}(\mathrm{OTf})_{3}, 2$ equiv. $\mathrm{K}_{2} \mathrm{CO} \mathrm{O}_{3}$ $0.5 \mathrm{mmol} 1,0.5 \mathrm{mmol}$ styrene derivative in $2 \mathrm{~mL} \mathrm{MeCN} / \mathrm{H}_{2} \mathrm{O} 4: 1$, degassed, irradiation with blue LEDs; isolated yields.

acetophenone radical. With exception of product 17, whose styrene precursor is known to be strongly prone to polymerization, all coupling products were obtained in good to excellent yields (up to $96 \%$ ). Interestingly, there is no recognizable difference for the coupling of styrenes with electron withdrawing (12-15) and electron donating substituents $(\mathbf{1 6}, \mathbf{1 8}, \mathbf{1 9})$. The direct comparison of the three different regioisomeric bromo styrenes (12-14) nicely shows the insensitivity of the transformation towards sterically hindrance being a typical advantage of radical coupling reactions. ${ }^{32}$

Even quaternary centers (e.g. tertiary alcohols) could be generated in excellent yields by either employing $\alpha$-methylstyrene (product 20) or 1,1-diphenylethylene (product 4). To further elucidate the broad scope of our approach for radical crosscouplings with styrenes, we then investigated the trapping of radicals derived from different substituted $\alpha$-acetoxy acetophenone precursors with a selection of four different styrenes (Scheme 6). Gratifyingly, we could obtain the desired products for all tested combinations within our " $4 \times 5$ matrix". While the yields for the combination of $\alpha$-acetoxy acetophenone 1 with these styrenes are all consistently very good to excellent (82$96 \%$; see Scheme 5 products: $\mathbf{8}, \mathbf{1 5}, \mathbf{1 6}, \mathbf{1 9})$ the difference in performance becomes more apparent for other, substituted $\alpha$-acetylated acetophenones (Scheme 6: acetophenones $\mathbf{I}-\mathbf{V}$ ). The cross-coupling of styrenes with $\alpha$-tetralone derivative $\mathbf{I}$, as precursor for secondary radicals, tolerates styrenes bearing an electron withdrawing group (21) as well as a mesomeric electron donating effect (22) (77-89\%). However, the yield decreases to $53 \%$ in combination with the sterically demanding and inductive electron donating tert-butyl substituent present (23). Interestingly, the electron donating methyl group (II) and the electron withdrawing chloro-substituent (III) did not show an opposing trend for their performance as coupling partners. According to this observed reactivity, the polarity match seems to be of minor importance for the success of this radical

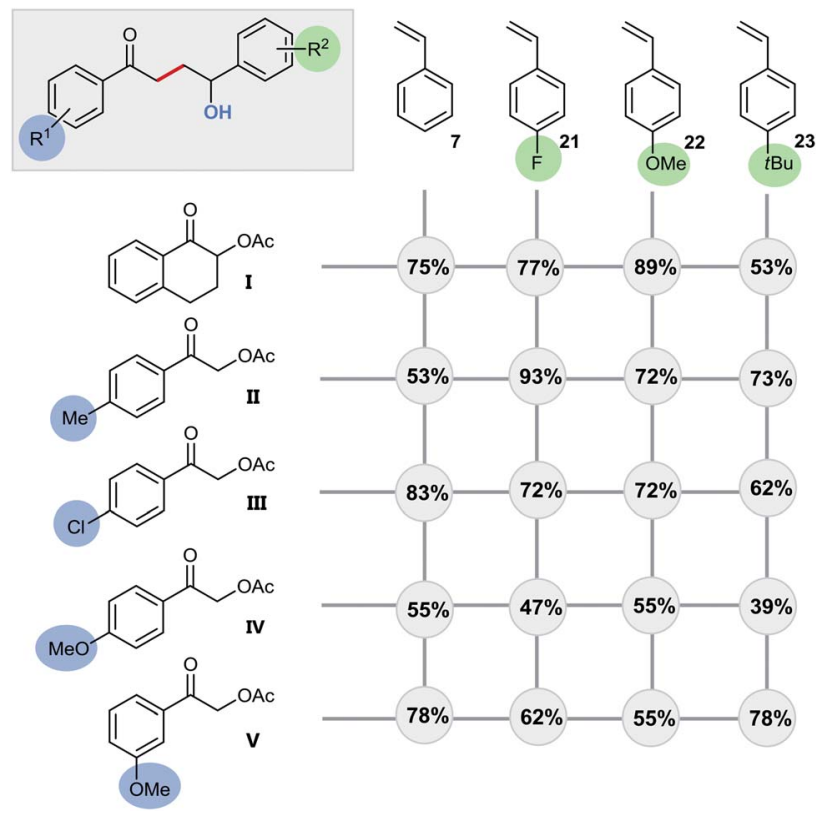

Scheme 6 Substrate scope for functionalizing, radical polar crosscoupling reaction with styrenes. Conditions: $0.5 \mathrm{~mol} \%$ fac- $\operatorname{lr}(\mathrm{ppy})_{3}$, $10 \mathrm{~mol} \% \mathrm{Nd}(\mathrm{OTf})_{3}, 2$ equiv. $\mathrm{K}_{2} \mathrm{CO}_{3}, 0.5 \mathrm{mmol}$ acetoxy substrate, $0.5 \mathrm{mmol}$ styrene derivative in $2 \mathrm{~mL} \mathrm{MeCN} / \mathrm{H}_{2} \mathrm{O} 4: 1$, degassed, irradiation with blue LEDs; isolated yields. 
transformation. However, the mesomeric effect of the paramethoxy substituent (acetophenone IV) shows a notable decrease of all yields being best explained by the lowering of the electron deficiency of the attacking alkyl radical, respectively of the substrate's carbonyl group for the initial SET reduction.

Altering the position of the substituent further illustrates this effect with the observed increased yield for the coupling with meta-methoxy substituted radical source $\mathbf{V}$ (Scheme 6/line 5: -I effect only).

\section{Conclusions}

In summary, we have developed a novel equimolar crosscoupling reaction of $\alpha$-acetoxy acetophenones and styrene derivatives with a subsequent Markovnikov functionalization to provide efficient access to versatile 1,4-substituted building blocks in good to excellent yields. The reaction was realized by the oxidative quenching of $f a c$ - $\operatorname{Ir}(\mathrm{ppy})_{3}$ in combination with effective synergistic activation of the carbonyl group with water and $\mathrm{Nd}(\mathrm{OTf})_{3}$. Detailed mechanistic investigations were performed, including cyclic voltammetry and Stern-Volmer experiments, to examine the LUMO-lowering effect in detail. Our mechanistic studies reveal the impact of radical source and choice of photocatalyst on both reactivity and selectivity and support the crucial importance of the deliberate application of fac-Ir(ppy $)_{3}$ as an "oxidative quenching cycle"-only catalyst for this challenging functionalizing cross-coupling reaction. Moreover, our studies shed further light on the often neglected, but critical role of aqueous solvent systems in photoredox reactions.

\section{Conflicts of interest}

There are no conflicts to declare.

\section{Acknowledgements}

This work was generously supported by the Deutsche Forschungsgemeinschaft (DFG, GRK 1626).

\section{Notes and references}

1 (a) D. Ravelli, S. Protti and M. Fagnoni, Carbon-Carbon Bond Forming Reactions via Photogenerated Intermediates, Chem. Rev., 2016, 116, 9850-9913; (b) M. H. Shaw, J. Twilton and D. W. C. MacMillan, Photoredox Catalysis in Organic Chemistry, J. Org. Chem., 2016, 81, 6898-6926.

2 J. K. Matsui, S. B. Lang, D. R. Heitz and G. A. Molander, Photoredox-Mediated Routes to Radicals: The Value of Catalytic Radical Generation in Synthetic Methods Development, ACS Catal., 2017, 7, 2563-2575.

3 (a) J. J. Douglas, M. J. Sevrin and C. R. J. Stephenson, Visible Light Photocatalysis: Applications and New Disconnections in the Synthesis of Pharmaceutical Agents, Org. Process Res. Dev., 2016, 20, 1134-1147; (b) M. D. Kärkäs, J. A. Porco Jr and C. R. J. Stephenson, Photochemical Approaches to
Complex Chemotypes: Applications in Natural Product Synthesis, Chem. Rev., 2016, 116, 9683-9747; (c) T. P. Nicholls, D. Leonori and A. C. Bissember, Applications of Visible Light Photoredox Catalysis to the Synthesis of Natural Products and Related Compounds, Nat. Prod. Rep., 2016, 33, 1248-1254.

4 A. H. Mashraqui and R. M. Kellogg, 3-Methyl-2,3dihydrobenzothiazoles as Reducing Agent. Dye Enhanced Photoreaction, Tetrahedron Lett., 1985, 26, 1449-1452.

5 For selected examples, see: (a) H. Huo, X. Shen, C. Wang, L. Zhang, P. Röse, L.-A. Chen, K. Harms, M. Marsch, G. Hilt and E. Meggers, Asymmetric Photoredox TransitionMetal Catalysis Activated by Visible Light, Nature, 2014, 515, 100-103; (b) N. Dange, A. H. Jatoi, F. Robert and Y. Landais, Visible-Light-Mediated Addition of Phenacyl Bromides onto Cyclopropenes, Org. Lett., 2017, 19, 36523655; (c) W. Chen, Z. Liu, J. Tian, J. Li, J. Ma, X. Cheng and G. Li, Building Congested Ketone: Substituted Hantzsch Ester and Nitrile as Alkylation Reagents in Photoredox Catalysis, J. Am. Chem. Soc., 2016, 138, 12312-12315; (d) N. Esumi, K. Suzuki, Y. Nishimoto and M. Yasuda, Synthesis of 1,4-Dicarbonyl Compounds from Silyl Enol Ethers and Bromocarbonyls, Catalyzed by an Organic Dye under Visible-Light Irradiation with Perfect Selectivity for the Halide Moiety over the Carbonyl Group, Org. Lett., 2016, 18, 5704-5707; (e) J. Cheng, X. Deng, G. Wang, Y. Li, $\mathrm{X}$. Cheng and G. Li, Intermolecular C-H Quaternary Alkylation of Aniline Derivatives Induced by Visible-Light Photoredox Catalysis, Org. Lett., 2016, 18, 4538-4541; (f) Q. Liu, H. Yi, J. Liu, Y. Yang, X. Zhang, Z. Zeng and A. Lei, Visible-Light Photocatalytic Radical Alkenylation of $\alpha$ Carbonyl Alkyl Bromides and Benzyl Bromides, Chem.-Eur. J., 2013, 19, 5120-5126; (g) H. Jiang, A. Cheng, Y. Zhang and S. Yu, De Novo Synthesis of Polysubstituted Naphthols and Furans Using Photoredox Neutral Coupling of Alkynes with 2-Bromo-1,3-dicarbonyl Compounds, Org. Lett., 2013, 15, 4884-4887; (h) X. Zhang, J. Qin, X. Huang and E. Meggers, One-Pot Sequential Photoredox Chemistry and Asymmetric Transfer Hydrogenation with a Single Catalyst, Eur. J. Org. Chem., 2018, 571-577 and references reported therein.

6 (a) A. Fábián, F. Ruff and Ö. Farkas, Mechanism of Nucleophilic Substitutions at Phenacyl Bromides with Pyridines. A Computational Study of Intermediate and Transition State, J. Phys. Chem., 2008, 21, 988-996. For an example of using 4-methoxy pyridine to supposedly improve leaving group properties of $\alpha$-bromopropionates in a photocatalytic reactions, see ref. $5 f$ and $(b) \mathrm{Y} . \mathrm{Su}$, L. Zhang and N. Jiao, Utilization of Natural Sunlight and Air in the Aerobic Oxidation of Benzyl Halides, Org. Lett., 2011, 13, 2168-2171.

7 P. Zhang, H. Le, R. E. Kyne and J. P. Morken, Enantioselective Construction of All-Carbo Quarternary Centers by BranchSelective Pd-Catalyzed Allyl-Allyl Cross-Coupling, J. Am. Chem. Soc., 2011, 133, 9716-9719.

8 M. Sheridan, Y. Wang, D. Wang, L. Troian-Gautier, C. J. Dares, B. D. Sherman and T. J. Meyer, Light-Driven 
Water Splitting Mediated by Photogenerated Bromine, Angew. Chem., Int. Ed., 2018, 57, 3449-3453.

9 For investigations on the direct UV light induced cleavage, see: J. Renaud and J. C. Scaiano, Hydrogen vs. Electron Transfer Mechanisms in the Chain Decomposition of Phenacyl Bromides. Use of Isotopic Labeling as a Mechanistic Probe, Can. J. Chem., 1996, 74, 1724-1730.

10 See ESI $\dagger$ for the cyclovoltammetric detection of bromide and its oxidation during the analysis of phenacyl bromide (upon initial reductive measuring direction).

11 (a) E. Speckmeier, C. Padié and K. Zeitler, Visible Light Mediated Reductive Cleavage of $\mathrm{C}-\mathrm{O}$ Bonds Accessing $\alpha$ Substituted Aryl Ketones, Org. Lett., 2015, 17, 4818-4821; (b) E. Speckmeier and K. Zeitler, Desyl and Phenacyl as Versatile, Photocatalytically Cleavable Protecting Group - A Classic Approach in a Different (Visible) Light, ACS Catal., 2017, 7, 6821-6826.

12 D. A. Nicewicz and D. W. C. MacMillan, Merging Photoredox Catalysis with Organocatalysis: The Direct Asymmetric Alkylation of Aldehydes, Science, 2008, 322, 77-80.

13 E. D. Nacsa and D. W. C. MacMillan, Spin-Center ShiftEnabled Direct Enantioselective $\alpha$-Benzylation of Aldehydes with Alcohols, J. Am. Chem. Soc., 2018, 140, 3322-3330.

14 For a short overview on photocatalytic, defunctionalizing SET reduction of $\alpha$-heteroatom carbonyl compounds, see: T. M. Monos, G. Magallanes, L. J. Sebren and C. R. J. Stephenson, Visible light mediated reductions of ethers, amines and sulfides, J. Photochem. Photobiol., A, 2016, 328, 240-248.

15 (a) H. Uoyama, K. Goushi, K. Shizu, H. Nomura and C. Adachi, Highly Efficient Organic Light-Emitting Diodes from Delayed Fluorescence, Nature, 2012, 492, 234-238; (b) J. Luo and J. Zhang, Donor-Acceptor Fluorophores for Visible-Light-Promoted Organic Synthesis: Photoredox/Ni Dual Catalytic $\mathrm{C}\left(\mathrm{sp}^{3}\right)-\mathrm{C}\left(\mathrm{sp}^{2}\right)$ Cross-Coupling, ACS Catal., 2016, 6, 873-877.

16 A. P. Taylor, R. P. Robinson, Y. M. Fobian, D. C. Blakemore, L. H. Jones and O. Fadeyi, Modern Advances in Heterocyclic Chemistry in Drug Discovery, Org. Biomol. Chem., 2016, 14, 6611-6637.

17 For selected recent reviews, see: (a) Special issue "Photoredox Catalysis in Organic Chemistry": Acc. Chem. Res. 2016, 49; (b) C. K. Prier, D. A. Rankic and D. W. C. MacMillan, Visible Light Photoredox Catalysis with Transition Metal Complexes: Applications in Organic Synthesis, Chem. Rev., 2013, 113, 5322-5363; (c) K. Zeitler, Photoredox Catalysis with Visible Light, Angew. Chem., Int. Ed., 2009, 48, 9785-9789.

18 Selected recent examples: (a) W. Liu, H. Cao, H. Zhang, H. Zhang, K. H. Chung, C. He, H. Wang, F. Y. Kwong and A. Lei, Organocatalysis in Cross-Coupling: DMEDACatalyzed Direct C-H Arylation of Unactivated Benzene, $J$. Am. Chem. Soc., 2010, 132, 16737-16740; (b) M. Nakajima, Q. Lefebvre and M. Rueping, Visible Light PhotoredoxCatalysed Intermolecular Radical Addition of $\alpha$-Halo Amides to Olefins, Chem. Commun., 2014, 50, 3619-3622. Review: (c) X.-W. Lan, N.-X. Wang and Y. Xing, Recent
Advances in Radical Difunctionalization of Simple Alkenes, Eur. J. Org. Chem., 2018, 5821-5851.

19 (a) M. H. V. Huynh and T. J. Meyer, Proton-Coupled Electron Transfer, Chem. Rev., 2007, 107, 5004-5064; (b) D. R. Weinberg, C. J. Gagliardi, J. F. Hull, C. Fecenko Murphy, C. A. Kent, B. C. Westlake, A. Paul, D. H. Ess, D. Granville McCafferty and T. J. Meyer, Proton-Coupled Electron Transfer, Chem. Rev., 2012, 112, 4016-4093; (c) K. E. C. Gentry and R. R. Knowles, Synthetic Applications of Proton-Coupled Electron Transfer, Acc. Chem. Res., 2016, 49, 1546-1556.

20 M. Nakajima, E. Fava, S. Loeschner, Z. Jiang and M. Rueping, Photoredox-Catalyzed Reductive Coupling of Aldehydes, Ketones, and Imines with Visible Light, Angew. Chem., Int. Ed., 2015, 54, 8828-8832.

21 Please also see Stern-Volmer studies (Fig. 2 and ESI $\dagger$ ) corroborating the pivotal role of water in the catalytic system.

22 For a recent review, see: K. N. Lee and M.-Y. Ngai, Recent Developments in Transition-Metal Photoredox-Catalysed Reactions of Carbonyl Derivatives, Chem. Commun., 2017, 53, 13093-13112.

23 (a) P. R. Schreiner, Metal-Free Organocatalysis through Explicit Hydrogen Bonding Interactions, Chem. Soc. Rev., 2003, 32, 289-296; (b) P. M. Pihko, Activation of Carbonyl Compounds by Double Hydrogen Bonding: An Emerging Tool in Asymmetric Catalysis, Angew. Chem., Int. Ed., 2004, 43, 2062-2064. For a seminal example of cooperative thiourea photoredox catalysis, see: (c) M. Neumann and K. Zeitler, A Cooperative Hydrogen-Bond-Promoted Organophotoredox Catalysis Strategy for Highly Diastereoselective, Reductive Enone Cyclization, Chem.Eur. J., 2013, 19, 6950-6955.

24 For other examples of successful carbonyl group activation with lanthanide-based triflates, also see: (a) J. Du, K. L. Skubi, D. M. Schultz and T. P. Yoon, A Dual-Catalysis Approach to Enantioselective [2+2] Photocycloadditions Using Visible Light, Science, 2014, 344, 392-396; (b) A. G. Amador, E. M. Sherbrook and T. P. Yoon, Enantioselective Photocatalytic [3+2] Cycloadditions of Aryl Cyclopropyl Ketones, J. Am. Chem. Soc., 2016, 138, 47224725; (c) T. P. Yoon, Photochemical Stereocontrol Using Tandem Photoredox-Chiral Lewis Acid Catalysis, Acc. Chem. Res., 2016, 49, 2307-2315.

25 For a photoredox transformation with a lanthanide activation of alkenyl pyridines, see: K. N. Lee, Z. Lei and M.-Y. Ngai, $\quad \beta$-Selective Reductive Coupling of Alkenylpyridines with Aldehydes and Imines via Synergistic Lewis Acid/Photoredox Catalysis, J. Am. Chem. Soc., 2017, 139, 5003-5006.

26 For recent reviews covering dual activation photocatalysis, see: (a) M. Neumann and K. Zeitler, Synergistic Visible Light Photoredox Catalysis, in Chemical Photocatalysis, ed. B. König, deGruyter, Berlin, 2013, p. 151; (b) M. N. Hopkinson, B. Sahoo, J.-L. Li and F. Glorius, Dual Catalysis See the Light: Combining Photoredox with Organo-, Acid, and Transition-Metal Catalysis, Chem.-Eur. 
J., 2014, 20, 3874-3886; (c) K. L. Skubi, T. R. Blum and T. P. Yoon, Dual Catalysis Strategies in Photochemical Synthesis, Chem. Rev., 2016, 116, 10035-10074; (d) J. Twilton, C. C. Le, P. Zhang, M. H. Shaw, R. W. Evans and D. W. C. MacMillan, The Merger of Transition Metal and Photocatalysis, Nat. Rev. Chem., 2017, 1, 0052.

27 For selected examples: (a) T. V. Chciuk, W. R. Anderson Jr and R. A. Flowers II, Proton-Coupled Electron Transfer in the Reduction of Carbonyls by Samarium Diiodide-Water Complexes, J. Am. Chem. Soc., 2016, 138, 8738-8741; (b) S. Shi, R. Szostak and M. Szostak, Proton-Coupled Electron Transfer in the Reduction of Carbonyls Using $\mathrm{SmI}_{2}-\mathrm{H}_{2} \mathrm{O}$ : Implications for the Reductive Coupling of Acyl-Type Ketyl Radicals with $\mathrm{SmI}_{2}-\mathrm{H}_{2} \mathrm{O}$, Org. Biomol. Chem., 2016, 14, 9151-9157; (c) T. V. Chciuk, W. R. Anderson and R. A. Flowers II, High-Affinity Proton Donors Promote Proton-Coupled Electron Transfer by Samarium Diiodide, Angew. Chem., Int. Ed., 2016, 55, 6033-6036.

28 The enhanced LUMO lowering effect by addition of lanthanide Lewis acids within the aqueous solvent system may also be considered as a case of "Lewis acid assisted Brønsted acid catalysis" (LBA) as classified by Yamamoto: H. Yamamoto and K. Futatsugi, "Designer Acids": Combined Acid Catalysis for Asymmetric Synthesis, Angew. Chem., Int. Ed., 2005, 44, 1924-1942.

29 (a) R. S. Nicholson, Theory and Application of Cyclic Voltammetry for Measurement of Electrode Reaction Kinetics, Anal. Chem., 1965, 37, 1351-1355; (b) A. Jutand, Contribution of Electrochemistry to Organometallic Catalysis, Chem. Rev., 2008, 108, 2300-2347; (c) For other mechanistic investigations by cyclic voltammetry see: T. Liedtke, P. Spannring, L. Riccardi and A. Gansäuer, Mechanism-Based Condition-Screening for Sustainable Catalysis in Single Electron Steps by Cyclic Voltammetry, Angew. Chem., Int. Ed., 2018, 57, 5006-5010. $30(a)$ See ref. $11 b$. For recent instructive examples, also see: $(b)$ A. J. Boyington, M.-L. Y. Riu and N. T. Jui, Anti-Markovnikov Hydroarylation of Unactivated Olefins via Pyridyl Radical Intermediate, J. Am. Chem. Soc., 2017, 139, 6582-6585; (c) R. A. Aycock, H. Wang and N. T. Jui, A Mild Catalytic System for Radical Conjugate Addition of Nitrogen Heterocycles, Chem. Sci., 2017, 8, 3121-3125.

31 (a) P. R. Ogilby, Singlet Oxygen: There Is Indeed Something New Under the Sun, Chem. Soc. Rev., 2010, 39, 3181-3209; (b) A. Greer, Christopher Foote's Discovery of the Role of Singlet Oxygen $\left[{ }^{1} \mathrm{O}_{2}\left({ }^{1} \Delta_{\mathrm{g}}\right)\right]$ in Photosensitized Oxidation Reactions, Acc. Chem. Res., 2006, 39, 797-804; (c) Q. G. Mulazzani, H. Sun, M. Z. Hoffman, W. E. Ford and M. A. J. Rodgers, Quenching of the Excited States of Ruthenium(II)-Diimine Complexes by Oxygen, J. Phys. Chem., 1994, 98, 1145-1150; (d) C. Tanielian, C. Wolff and M. Esch, Singlet Oxygen Production in Water: Aggregation and Charge-Transfer Effects, J. Phys. Chem., 1996, 100, 6555-6560.

32 (a) G. L. Lackner, K. W. Quasdorf and L. E. Overman, Direct Construction of Quaternary Carbons from Tertiary Alcohols via Photoredox-Catalyzed Fragmentation of tert-Alkyl $\mathrm{N}$ Phthalimioyl Oxalates, J. Am. Chem. Soc., 2013, 135, 1534215345; (b) L. Chu, C. Ohta, Z. Zuo and D. W. C. MacMillan, Carboxylic Acids as A Traceless Activation Group for Conjugate Additions: A Three-Step Synthesis of (士)-Pregabalin, J. Am. Chem. Soc., 2014, 136, 10886-10889; (c) C. C. Nawrat, C. R. Jamison, Y. Slutskyy, D. W. C. MacMillan and L. E. Overman, Oxalates as Activating Groups for Alcohols in Visible Light Photoredox Catalysis: Formation of Quaternary Centers by RedoxNeutral Fragment Coupling, J. Am. Chem. Soc., 2015, 137, 11270-11273. 